\title{
Effectiveness of intra-articular hyaluronic acid versus corticosteroids in knee osteoarthritis: a comparative study
}

\author{
Mithilesh A. Nikam*, Paresh V. Patil, Priyambada Kumar
}

Department of Orthopedics, Krishna Institute of Medical Sciences, Karad, Maharashtra, India

Received: 11 January 2022

Accepted: 07 February 2022

\section{*Correspondence:}

Dr. Mithilesh A. Nikam,

E-mail: mithinikam@gmail.com

Copyright: (C) the author(s), publisher and licensee Medip Academy. This is an open-access article distributed under the terms of the Creative Commons Attribution Non-Commercial License, which permits unrestricted non-commercial use, distribution, and reproduction in any medium, provided the original work is properly cited.

\section{ABSTRACT}

Background: Osteoarthritis (OA) is the largest cause of disability worldwide and the most common cause of knee discomfort. OA is a chronic, progressive joint disease marked by articular cartilage deterioration and secondary hyperosteogeny. OA affects 35 percent of those over the age of 65 and produces considerable pain in the knee joint. The patient with OA not only suffers from chronic pain, stiffness, and reduced movement, physical and/or mental comorbidity, but also has a direct impact on their quality of life.

Methods: 72 patients with symptomatic osteoarthritis of unilateral knee joint (pain $>3$ months) were included in the present study. They were randomly divided into two groups; group $\mathrm{A}(\mathrm{n}=36)$ included patients who were given intraarticular injection hyaluronic acid and group B $(n=36)$ included those who were given intra-articular corticosteroid injection. All the data was compared both within the group as well as with one another at different follow up time.

Results: There was no significant difference in the basic demographic distribution in both groups. Female sex predilection was seen in the present study. In patients receiving hyaluronic acid (HA), mean baseline visual analog scale (VAS) score was noted to be 7.45 \pm 1.4 . Then at 2 weeks, 6 weeks, 3 months and 6 months follow up the mean VAS score was 3.4 $\pm 1.3,2.78 \pm 1.1,3.71 \pm 1.4$ and $3.90 \pm 1.2 ; \mathrm{p}<0.05)$.

Conclusions: Steroids provide an acute symptomatic relief but their benefits are short lasting. On the other hand, HA provides long lasting therapeutic pain relief.

Keywords: Intra-articular corticosteroids, Hyaluronic acid, Kellegren and Lawrence classification, Osteoarthritis, WOMAC, VAS score

\section{INTRODUCTION}

Osteoarthritis (OA) is the largest cause of disability worldwide and the most common cause of knee discomfort. OA is a chronic, progressive joint disease marked by articular cartilage deterioration and secondary hyperosteogeny. ${ }^{1} \mathrm{OA}$ affects 35 percent of those over the age of 65 and produces considerable pain in the knee joint. ${ }^{2}$ The patient with OA not only suffers from chronic pain, stiffness, and reduced movement, physical and/or mental co-morbidity, but also has a direct impact on their quality of life. ${ }^{3}$
Because of its immense intricacy and interplay of numerous biological elements such as genetic changes, sex hormone shortage, and ageing, OA is poorly understood. ${ }^{4}$ Many recent studies have focused on molecular markers that have been linked to chondrocyte senescence caused by stress. ${ }^{5}$ The reasons of cartilage breakdown that leads to OA have been suggested to be a variety of mechanical and metabolic processes. In the pathophysiology of knee OA, cytokines and other growth factors (GF) may also play a role in the regulation of catabolic and anabolic processes. Interleukin-1 and tumour necrosis factor, which induce proteolytic digestion of articular cartilage, are the major mediators of the catabolic process. 
Clinical recommendations propose a variety of conservative treatment options, including both pharmacological and non-pharmacological options, to relieve pain and restore joint function. ${ }^{6}$ The majority of knee OA researchers have concentrated on tertiary management options, such as pain reduction with effective medication therapies (NSAIDs, chondroitin supplements, and so on). NSAIDs have been shown to be useful in treating OA pain, but long-term usage has been linked to potentially serious side effects. Furthermore, because of pharmacogenomics interactions, their tailored response is highly heterogeneous. ${ }^{7}$ There is no definitive cure for OA, with the exception of knee joint replacement, which is usually reserved for end-stage disease. If pain persists after rest or medicine and other non-invasive interventions have failed, intra-articular injections of a variety of medications may be used as a last resort before surgery. Hyaluronic acid (HA), corticosteroids (CS), and blood-derived products like platelet-rich plasma are examples of these (PRP).

Hyaluronate is a high-molecular-weight, widely distributed substance found in cartilage and synovial fluid. It has several functions in the joint, including lubricating, functioning as a gap filler to keep the joint open, and regulating cellular activity including protein binding. ${ }^{8}$ The endogenous $\mathrm{HA}$ in the joint depolymerizes from a high molecular weight (6500-10,900 kDa) to a lower molecular weight $(2700-4500 \mathrm{kDa})$ as $\mathrm{OA}$ progresses. ${ }^{9,10}$ This reduces the mechanical and viscoelastic properties of the synovial fluid in the afflicted joint.

Intra-articular HA injections have been shown to improve joint lubrication and synovial fluid viscosity, normalise hyaluronan synthesis, block proteoglycan breakdown, and have analgesic and anti-inflammatory effects in the treatment of OA. ${ }^{11-14}$

Intra-articular corticosteroids have anti-inflammatory properties because they inhibit inflammatory cytokines as well as the mechanisms that lead to their production. ${ }^{15}$ The duration effect of CS, on the other hand, is much less than the recommended interval between doses. ${ }^{16}$ As a result, the short-term impacts are acceptable; nevertheless, the longterm implications need to be investigated further.

The goal of this study is to compare the efficacy of intraarticular HA injection with corticosteroid injection in patients with grade II and grade III knee OA (according to Kellgren Lawrence classification).

\section{METHODS}

72 patients with symptomatic OA of unilateral knee joint (pain >3 months) were included in the present study. They were randomly divided into two groups; group A $(n=36)$ included patients who were given intra-articular injection HA and group B $(n=36)$ included those who were given intra-articular corticosteroid injection.
The inclusion criteria were: age above 50 years, of any sex, and patients with radiographic evidence of grade II/III OA of knee (according to Kellegren Lawrence grading of OA).

The exclusion criteria were: patients diagnosed with pathological conditions like rheumatoid arthritis and pseudogout; patients having knee flexion contracture greater than 20 degrees; patients with major axial deviation, varus or valgus $>5$ degrees; patients with systemin disorders like diabetes mellitus, thyroid dysfunction, severe cardiovascular diseases; patients with history of ipsilateral hip/knee arthroplasty surgery in the past; patients with history of any previous intra-articular injection in knee joint; patients with bleeding diathesis; patients with local skin infection/pathology; and patients with immunosuppression.

All patients who fulfilled the inclusion and exclusion criteria were recruited for the study. The present study was carried from June 2020 to June 2021 in Krishna Institute of Medical Sciences, "deemed to be university" Karad. All the participants had signed the written and informed consent before enrolling in the study. This randomized prospective comparative study was approved by the institutional ethical committee.

Patients in group A $(n=36)$ and were given Intra-articular $6 \mathrm{ml}\left(48 \mathrm{mg}\right.$ ) sodium hyaluronate (Hylasto one $\left.{ }^{\mathrm{TM}}\right)$. It contains high molecular weight (HMW) elastoviscous fluid with highly cross-linked long chain polymers.

Patients in group B $(\mathrm{n}=36)$ were given $1 \mathrm{ml}(40 \mathrm{mg})$ triamcinolone acetonide (kenacort ${ }^{\mathrm{TM}}$ ) mixed with $1 \mathrm{ml}$ of $2 \%$ lignocaine.

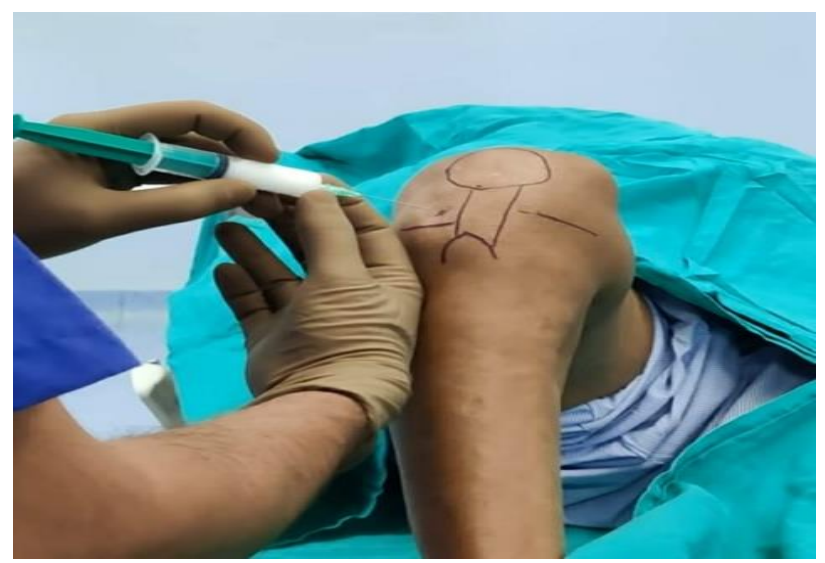

Figure 1: Antero-lateral portal for intra-articular injection in the knee joint.

The procedure was performed with the patient in supine position, with the affected knee flexed to 90 degrees. Sterile scrubbing, painting and draping of the local part was performed. All the injections were given in the intraarticular space via the anterolateral portal after aspiration of synovial fluid for confirmation. Strict aseptic precautions and no-touch technique of the needle was 
followed for the procedure. Patients in both groups were advised to wear a knee cap ubiquitously.

Baseline data was collected before starting the treatment as per visual analog scale (VAS) and WOMAC score for evaluation of pain and function, and all patients were called for follow up at 2 weeks, 6 weeks, 3 months and 6 months post treatment. All the data was compared both within the group as well as with one another at different follow-up time.

Data was entered in Microsoft excel spreadsheet and variables was analysed using statistical package for the social sciences (SPSS) software. Continuous variables were presented as mean \pm standard deviation (SD). Intergroup comparisons were made using the unpaired student's t-test for normally distributed variable. All hypothesis tests were two-tailed. A value of $p<0.05$ was considered statistically significant.

\section{RESULTS}

There was no significant difference in the basic demographic distribution in both groups. Female sex predilection was seen in the present study. Right sided was predominantly affected.

Table 1: Showing age distribution of patients.

\begin{tabular}{|lll|}
\hline Parameters & $\begin{array}{l}\text { Group A } \\
\text { (HA) \% }\end{array}$ & $\begin{array}{l}\text { Group B (steroid } \\
\text { injection) \% }\end{array}$ \\
\hline Females (n) & $23(63.88)$ & $24(66.66)$ \\
\hline Males (n) & $13(36.12)$ & $12(33.34)$ \\
\hline $\begin{array}{l}\text { Affected side } \\
\text { ratio (right: left) }\end{array}$ & $3: 1$ & $2.5: 1$ \\
\hline KL grade II & $20(62.5)$ & $19(59.37)$ \\
\hline KL grade III & $12(37.5)$ & $13(40.625)$ \\
\hline
\end{tabular}

Comparison of VAS scores in both groups (Table 2) was presented as mean \pm standard deviation. Similarly WOMAC knee score in the two groups were analysed statistically (Table 3). Baseline pre-treatment data for mean VAS score and WOMAC score were similar for both groups $(\mathrm{p}<0.05)$.

It was seen that at 2 weeks post treatment, there was a sharp decline in the mean VAS score in corticosteroid group which was significantly higher than the improvement in HA group (mean VAS in HA group $=3.4 \pm 1.3$; mean VAS in steroid group $=2.65 \pm 1.7$; $\mathrm{p}<0.001)$. However, at 6 weeks follow up, and at each follow up after that, the improvement in VAS score is significantly higher in the HA group as compared to the steroid group $(\mathrm{p}<0.05)$. Also, it was noted that the beneficial effect of corticosteroid weaned off beyond 3 months, and the VAS score started to show a significant rise as compared to the previous readings in the same group (mean VAS in steroid group at 3 months $=0.55 \pm 1.4$ and at 6 months $=5.96 \pm 1.6 ; \mathrm{p}<0.001$ ).
Table 2: Comparison of VAS scores in both groups.

\begin{tabular}{|lll|}
\hline Parameters & $\begin{array}{l}\text { Mean VAS } \\
\text { score in } \\
\text { group A (HA) }\end{array}$ & $\begin{array}{l}\text { Mean VAS score } \\
\text { in group B } \\
\text { (steroid injection) }\end{array}$ \\
\hline $\begin{array}{l}\text { Pre- } \\
\text { treatment }\end{array}$ & $7.45 \pm 1.4$ & $7.88 \pm 1.2$ \\
\hline At 2 weeks & $3.4 \pm 1.3$ & $2.65 \pm 1.7$ \\
\hline At 6 weeks & $2.78 \pm 1.1$ & $2.85 \pm 1.6$ \\
\hline At 3 months & $3.71 \pm 1.4$ & $4.55 \pm 1.4$ \\
\hline At 6 months & $3.90 \pm 1.2$ & $5.96 \pm 1.6$ \\
\hline
\end{tabular}

Similar findings were noted with WOMAC score. It was seen that at 2 weeks post treatment, there was a sharp decline in the mean WOMAC score in corticosteroid group which was significantly higher than the improvement in HA group (mean WOMAC score in HA group $=64.42 \pm 7.9$; in steroid group $=58.80 \pm 8.3 ; \mathrm{p}<0.001)$. However, at 6 weeks follow up, and at each follow up after that, the improvement in WOMAC score is significantly higher in the HA group as compared to the steroid group $(\mathrm{p}<0.05)$. Also, it was noted that the beneficial effect of corticosteroid weaned off beyond 3 months, and the WOMAC score started to show a significant rise as compared to the previous readings in the same group (mean WOMAC score at 3 months in steroid group $=65.37 \pm 7.9$ and at 6 months $=71.35 \pm 8.1 ; \mathrm{p}<0.001$ ).

Table 3: Comparison of WOMAC scores in both groups.

\begin{tabular}{|lll|}
\hline Parameters & $\begin{array}{l}\text { Mean WOM- } \\
\text { AC score in } \\
\text { group A (HA) }\end{array}$ & $\begin{array}{l}\text { Mean WOMAC } \\
\text { score in group B } \\
\text { (steroid injection) }\end{array}$ \\
\hline $\begin{array}{l}\text { Pre- } \\
\text { treatment }\end{array}$ & $78.94 \pm 8.7$ & $74.86 \pm 7.4$ \\
\hline At 2 weeks & $64.42 \pm 7.9$ & $58.80 \pm 8.3$ \\
\hline At 6 weeks & $58.23 \pm 9.3$ & $59.45 \pm 8.2$ \\
\hline At 3 months & $59.11 \pm 7.3$ & $65.37 \pm 7.9$ \\
\hline At 6 months & $59.74 \pm 8.8$ & $71.35 \pm 8.1$ \\
\hline
\end{tabular}

\section{DISCUSSION}

The most common type of arthritis or degenerative joint disease is OA. It's a prevalent chronic, progressive musculoskeletal condition marked by articular cartilage degradation over time. It is the most common cause of long-term impairment. The disease primarily affects the middle-aged and elderly, while it can also afflict younger persons as a result of injury or overuse. Because age is the biggest predictor of disease, a longer life expectancy means a higher risk of developing the disease. ${ }^{18} \mathrm{OA}$ patients experience discomfort and loss of function. Objectives of OA management include reducing pain, inflammation, slowing cartilage deterioration, improving function, and reducing disability. ${ }^{19}$ Steroids are antiinflammatory as well as immunosuppressive. These drugs work by interfering with nuclear steroid receptors, interrupting the inflammatory and immunological systems 
at many points. It reduces erythema, heat, oedema, and discomfort in inflammatory joints and increases the relative viscosity of joint fluid in clinical studies. ${ }^{20}$ During the flare of knee OA, it reduces acute episodes of pain and enhances joint mobility. ${ }^{21}$

For visco-supplementation, HA is utilised in a variety of formulations. We utilised the abbreviation HA to refer to sodium hyaluronate in our research. Synovial fluid contains a lot of HMW HA. It provides lubrication to the joint and nutrition to the hyaline cartilage and is approximately 3-4 $\mathrm{ml}$ in each knee. Anti-angiogenic, antiinflammatory, and anti-immunogenic effects of high molecular weight HA. ${ }^{22}$ HMW HA's high viscosity gives the fluid viscoelastic qualities, which are required for minimal friction on the joint surface. ${ }^{23} \mathrm{HA}$ preparations are currently available in a variety of molecular weights. LMW preparations (0.5-1.5 million Dalton) have a greater ability to diffuse through the synovium's extracellular matrix (ECM) and interact with synovial cells. ${ }^{24}$

The goal of this study was to compare the effectiveness of intra-articular HA injections vs intra-articular steroid injections in providing pain and functional relief in individuals with grade II/III OA (as defined by Kellegren and Lawrence). For the same, VAS and WOMAC knee scores were employed. ${ }^{25}$ Values were noted pre-treatment and subsequently at each follow up.

In patients receiving $\mathrm{HA}$, mean baseline VAS score was noted to be $7.45 \pm 1.4$. Then at 2 weeks, 6 weeks, 3 months and 6 months follow up the mean VAS score was 3.4 \pm 1.3 , $2.78 \pm 1.1,3.71 \pm 1.4$ and $3.90 \pm 1.2 ; \mathrm{p}<0.05)$. The above results shows that the maximum effect of hyaluronic acid was noted to be from 6 weeks to 3 months. However there beneficial effect was found to be persisting even up till 6 months. Similarly using the WOMAC knee score the mean score at first visit the was $78.94 \pm 8.7$ then at 2 weeks, 6 weeks, 3 months and $6^{\text {th }}$ months the mean WOMAC knee score was $64.42 \pm 7.9,58.23 \pm 9.3,59.11 \pm 7.3$ and $59.74 \pm 8.8$; $\mathrm{p}<0.05)$.

In patients receiving intra-articular corticosteroid, mean baseline VAS score was noted to be $7.88 \pm 1.2$. Then at 2 weeks, 6 weeks, 3 months and 6 months follow up the mean VAS score was $2.65 \pm 1.7,2.85 \pm 1.6,4.55 \pm 1.4$ and $5.96 \pm 1.6 ; \mathrm{p}<0.001)$. The above results shows that the maximum effect of intra-articular corticosteroid was noted to be from 2 weeks to 6 weeks. At 3 months and 6 months the effect started to wean off. Similarly using the WOMAC knee score the mean score at first visit the was $74.86 \pm 7.4$ then at 2 weeks, 6 weeks, 3 months and 6 th months the mean WOMAC knee score was $58.80 \pm 8.3$, 59.45 \pm 8.2 , $65.37 \pm 7.9$ and $71.35 \pm 8.1 ; \mathrm{p}<0.001)$.

In a comparison of methylprednisolone and HA on 40 patients, Leardini et al observed that HA had a longer action than prednisolone. ${ }^{26}$ They predicted that HA will be a game-changer in the treatment of knee OA. The trial was just two months long, and the outcomes were measured using the VAS score. Both therapies were well tolerated, with no signs of local or systemic side effects. VAS ratings were used in the Jones et al study to assess pain, stiffness duration, range of motion, joint effusion, local heat, synovial thickness, and joint-line and periarticular tenderness. During the 6-month follow-up period, the hyaluronic acid group reported much less discomfort than the steroids group. ${ }^{27}$ Another study done by Caborn et al, in 2004 to assess prospectively the efficacy and tolerability of hylan G-F 20 (HG-F 20; Synvisc) and intraarticular triamcinolone hexacetonide for treatment of OA knee pain in a 26 week, randomized, multicenter, evaluator-blind study. The study concludes that maximum pain relief occurred at 1-2 weeks for triamcinolone hexacetonide and at week 12 for HG-F 20. At weeks 12 and 26, HG-F 20 was significantly better than triamcinolone hexacetonide. They concluded that Viscosupplementation with HG-F 20 resulted in a longer duration of effect than triamcinolone hexacetonide with a comparable tolerability profile. ${ }^{28}$ Merolla et al used steroid and HA injections in the OA of shoulder and found similar results as of knee OA. ${ }^{29}$ The effect of steroid decreased after 1 month, but HA remains up to 6 months.

\section{CONCLUSION}

The present study demonstrates that intra-articular administration of $\mathrm{HA}$ and steroids act as effective palliative agents in case of osteoarthritis of the knee. However, steroids provide an acute symptomatic relief but their benefits are short lasting. On the other hand, HA provides long lasting therapeutic pain relief. Keeping the limitations of this study in mind; a short follow up period and small sample size; it is safe to conclude that steroid when given intra-articular can give pain relief for about 12 weeks while HA provides significant pain relief until six months after the injection.

\section{Funding: No funding sources}

Conflict of interest: None declared

Ethical approval: The study was approved by the institutional ethics committee

\section{REFERENCES}

1. Poole AR, Rizkalla G, Ionescu M. Osteoarthritis in the human knee: a dynamic process of cartilage matrixdegradation, synthesis and reorganization. Agents Actions. 1993;39:3-13.

2. Ringdahl E, Pandit S. Treatment of knee osteoarthritis. Am Fam Physician. 2011;83:1287-92.

3. Moskowitz RW. The burden of osteoarthritis: clinical and quality-of-life issues. Am $\mathrm{J}$ Manag Care. 2009;15(8):223-9.

4. Herrero-Beaumont $\mathrm{G}$, Roman-Blas JA, Bruyère $\mathrm{O}$, Cooper C, Kanis J, Maggi S, Rizzoli R, Reginster JY. Clinical settings in knee osteoarthritis: Pathophysiology guides treatment. Maturitas. 2017;96:54-57. 
5. Zhang W, Moskowitz RW, Nuki G, Abramson S, Altman RD, Arden N, et al. OARSI recommendations for the management of hip and knee osteoarthritis, Part II: OARSI evidence-based, expert consensus guidelines. Osteoarthritis Cartilage. 2008;16(2):137-62.

6. Buckwalter JA, Mankin HJ. Articular cartilageDegeneration and osteoarthritis, repair, regeneration, and transplantation. Instr Course Lect. 1998;47:487504.

7. Brosseau L, Taki J, Desjardins B, Thevenot O, Fransen M, Wells GA, et al. The Ottawa panel clinical practice guidelines for the management of knee osteoarthritis. Part three: aerobic exercise programs. Clin Rehabil. 2017;31(5):612-24.

8. Ayhan E, Kesmezacar H, Akgun I. Intraarticular injections (corticosteroid, hyaluronic acid, platelet rich plasma) for the knee osteoarthritis. World $\mathrm{J}$ Orthop. 2014;5(3):351-61.

9. Altman RD, Manjoo A, Fierlinger A, Niazi F, Nicholls $M$. The mechanism of action for hyaluronic acid treatment in the osteoarthritic knee: a systematic review. BMC Musculoskelet Disord. 2015;16:321.

10. Stern R, Jedrzejas MJ. Hyaluronidases: their genomics, structures, and mechanisms of action. Chem Rev. 2006;106(3):818-39.

11. Day R, Brooks P, Conaghan PG, Petersen M; Multicenter Trial Group. A double blind, randomized, multicenter, parallel group study of the effectiveness and tolerance of intraarticular hyaluronan in osteoarthritis of the knee. J Rheumatol. 2004;31(4):775-82.

12. Shimazu A, Jikko A, Iwamoto M, Koike T, Yan W, Okada Y, et al. Effects of hyaluronic acid on the release of proteoglycan from the cell matrix in rabbit chondrocyte cultures in the presence and absence of cytokines. Arthritis Rheum. 1993;36(2):247-53.

13. Gotoh S, Onaya J, Abe M, Miyazaki K, Hamai A, Horie K, Tokuyasu K. Effects of the molecular weight of hyaluronic acid and its action mechanisms on experimental joint pain in rats. Ann Rheum Dis. 1993;52(11):817-22.

14. Asari A, Miyauchi S, Matsuzaka S, Ito T, Kominami E, Uchiyama Y. Molecular weight-dependent effects of hyaluronate on the arthritic synovium. Arch Histol Cytol. 1998;61(2):125-35.

15. Creamer P. Intra-articular corticosteroid treatment in osteoarthritis. Curr Opin Rheumatol. 1999;11:41721.

16. Bannuru RR, Natov NS, Obadan IE, Price LL, Schmid CH, McAlindon TE. Therapeutic trajectory of hyaluronic acid versus corticosteroids in the treatment of knee osteoarthritis: a systematic review and meta-analysis. Arthritis Rheum. 2009;61(12):1704-11.
17. Kohn MD, Sassoon AA, Fernando ND. Classifications in Brief: Kellgren-Lawrence Classification of Osteoarthritis. Clin Orthop Relat Res. 2016;474(8):1886-93.

18. Jordan KM, Arden NK, Doherty M, Bannwarth B. An Evidence Based Approach to the Management of Knee Osteoarthritis: Report of a Task Force of the Standing Committee for International Clinical Studies Including Therapeutic Trials (ESCISIT). Ann Rheum Dis. 2003;62:1145-55.

19. Hochberg MC, McAlindon T, Felson DT. Systemic and topical treatments. In Osteoarthritis: New insights. Part 2: Treatment approaches. Ann Intern Med. 2000;133:726-37.

20. Ostergaard M., Halberg P. Intra-articular corticosteroids in arthritic disease: a guide to treatment. BioDrugs. 1998;9(2):95-103.

21. Rozental TD, Sculco TP. Intra-articular corticosteroids: an updated overview. Am J Orthop (Belle Mead NJ). 2000;29(1):18-23.

22. Zhang FJ, Luo W, Gao SG. Expression of CD44 in articular cartilage is associated with disease severity in knee OA. Mod Rheumatol. 2013;23(6):1186-91.

23. Musumeci G, Loreto C, Carnazza ML. Acute injury affects lubricin expression in knee menisci: an immunohistochemical study. Ann Anat. 2013;195(2):151-8.

24. Bagga H, Burkhardt D, Sambrook P, March L. Longterm effects of IA hyaluronan on synovial fluid in osteoarthritis of the knee. J Rheumatol. 2006;33(5):946-50.

25. Bellamy N. WOMAC osteoarthritis index users guide. Queensland, Australia: University of Queensland. 2000;1-43.

26. Leardini G, Mattara L, Franceschini M, Perbellini A. Intra-articular treatment of knee OA. A comparative study between hyaluronic acid and 6-methyl prednisolone acetate. Clin Exp Rheumatol. 1991;9(4):375-81.

27. Jones AC, Pattrick M, Doherty S, Doherty M. Intraarticular HA compared to intra-articular THA in inflammatory knee OA. Osteoarthritis Cartilage. 1995;3(4):269-73.

28. Caborn D, Rush J, Lanzer W, Parenti D, Murray C; Synvisc 901 Study Group. A randomized, singleblind comparison of the efficacy and tolerability of hylan G-F 20 and triamcinolone hexacetonide in patients with osteoarthritis of the knee. J Rheumatol. 2004;31(2):333-43.

29. Merolla G, Sperling JW, Paladini P, Porcellini G. Efficacy of Hylan G-F 20 versus 6methylprednisolone acetate in painful shoulder osteoarthritis: a retrospective controlled trial. Musculoskelet Surg. 2011;95(3):215-24.

Cite this article as: Nikam MA, Patil PV, Kumar P. Effectiveness of intra-articular hyaluronic acid versus corticosteroids in knee osteoarthritis - a comparative study. Int J Res Orthop 2022;8:192-6. 